\title{
O Que a Ciência Pode Fazer pelo DesenVOLVIMENTO SUSTENTÁVEL?
}

\author{
M. G. K. MENON \\ (Conselho Internacional de Unióes Cientificas, Paris, Franfa)
}

\begin{abstract}
A Conferência das Naçóes Unidas sobre Meio-Ambiente e DeA senvolvimento (UNCED) - no Brasil, ECO-92 - , ocorreu no Rio de Janeiro, Brasil, em junho de 1992 . Sua raison $d^{3}$ 'tre veio do Relatório da Comissáo Mundial sobre Meio-Ambiente e Desenvolvimento, presidido pela $\mathrm{sr}^{\mathrm{a}}$ Brundtland. $O$ relatório pedia uma agenda global de mudança da forma com que se olha para as questóes de pobreza, crescimento econômico e degradação ambiental e industrializaçáo. Em particular, demandava processo de desenvolvimento que fosse sustentável e em harmonia com os sistemas terrestres de apoio à vida e com a capacidade destes. Colocou o desenvolvimento em um contexto muito mais amplo que o econômico: desenvolvimento deve propiciar eqüidade dentro da geraçáo presente e também entre geraçóes. Focalizou a necessidade de ser alterado o curso dos padróes atuais de desenvolvimento e consumo, caso se queira garantir a sustentabilidade do processo. A ECO-92 foi o esforço para discutir esses temas no mais alto nível intergovernamental e apoiada em significativo trabalho de preparação.
\end{abstract}

A Secretaria Geral da ECO-92 solicitou ao Conselho Internacional de Uniōes Científicas (ICSU) que fosse seu principal órgáo de aconselhamento científico. Para permitir que o ICSU realizasse essa tarefa, ele mesmo promoveu um encontro, realizado em Viena, no mês de novembro de 1991, denominado ASCEND 21 (Uma Agenda para MeioAmbiente e Desenvolvimento para o Século 21). Este foi um esforço para reunir um grupo de indivíduos de alto nível, não apenas de diferentes disciplinas das ciências nacionais que se encontram sob as áreas de atuação do ICSU, mas também de vários segmentos relacionados às ciências sociais, engenharia, negócios e indústria, organizaçōes intergovernamentais e náo-governamentais etc. Teve por objetivo examinar como a ciência poderia entrar em contato com os emergentes problemas do meio-ambiente planetário, dado o reconhecimento de que é preciso um desenvolvimento sustentável conforme caminhamos para o próximo século. Não era apenas questáo de se fazer boa ciência, mas de permitir 
que ela se tornasse efetiva nos contextos de economia, política, cultura e das forças principais que norteiam as expectativas e aspiraçóes humanas.

O resultado da ECO-92 incluiu a Declaraçáo do Rio, composta de certos princípios que poderiam governar a transiçáo para a sustentabilidade. Houve também a Convenção sobre a Mudança do Clima, baseada em trabalho muito detalhado feito pelo Painel Intergovernamental sobre Mudança no Clima, cujo relatório foi endossado pela Segunda Conferência sobre o Clima Mundial, realizada em fins de 1990, em Genebra. O objetivo da Convençáo é garantir que medidas sejam tomadas de forma que as atividades humanas não acarretem alteraçóes climáticas em uma escala que possa afetar o desenvolvimento sustentável a longo prazo e, particularmente, atividades que possam levar a grandes incrementos do efeito estufa na atmosfera terrestre. Outra convenção tratou de Diversidade Biológica. Esta, essencialmente, reconhece a importância da biodiversidade para o desenvolvimento sustentável a longo prazo e o fato de que a forma atual do desenvolvimento está levando à sua redução. Outro resultado do Rio foi a Declaração de Princípios sobre Florestas.

A peça central das discussōes no Rio foi a Agenda 21, que é, essencialmente, um amplo programa de ação cobrindo temas de desenvolvimento e meio-ambiente em uma base integrada. O ICSU ajudou na preparação do capítulo sobre ciência (35), da Agenda 21, denominado Ciência para um Desenvolvimento Sustentável. Além desse capítulo específico, existem muitos outros, setoriais, nos quais a ciência tem um papel importante. Por exemplo: proteçáo da atmosfera, planejamento e gerenciamento de recursos do solo, recursos oceânicos e de água doce, conservação da biodiversidade, gerenciamento ambientalmente seguro da biotecnologia, combate ao desflórestamento, gerenciamento de ecossistemas frágeis, de produtos químicos tóxicos, de detritos perigosos, de detritos radiativos etc. Existe um capítulo específico, o 31, intitulado $A$ Comunidade Cientifica e Tecnológica, que desenvolve o tema da desejada colaboração entre ciência, política e informaçáo pública; outro, o 36 , sobre a promoçáo da educaçáo, a consciência popular e o treinamento; outro ainda, o 37, sobre os mecanismos nacionais e a cooperaçăo internacional para o desenvolvimento de capacitação nos países em desenvolvimento. Este último ponto é relevante para a comunidade científica, do ponto de vista da capacitaçáo essencial para tornar real um desenvolvimento sustentável. O tema da ciência e da tecnologia voltadas para o desenvolvimento sustentável permeia toda a Agenda 21, tornando-a um bom livro que trata problemas e questóes sobre os quais nós, como 
comunidade científica, devemos nos posicionar. Dado o que foi dito acima, podemos nos perguntar: $O$ que a ciência pode fazer pelo desenvolvimento sustentável?

Por um lado, a ciência tem um importante papel a desempenhar em observação, monitoração e análise das mudanças globais que estão acontecendo, mantendo a sociedade informada. Para isso, precisa de referência a respeito dos vários aspectos que definem o sistema terrestre. Esse é o principal papel que a ciência vem desempenhando até hoje. De fato, todo nosso conhecimento atual sobre as potenciais alteraçôes climáticas e suas implicaçóes, e também alteraçóes na biodiversidade, vem do cuidadoso trabalho científico, sem o qual teria sido muito difícil, para a sociedade, tomar conhecimento desses assuntos.

Começamos a cada vez mais reconhecer o fato de estarmos lidando com um complexo sistema terrestre, que possui uma miríade de elos e interconexóes entre seus componentes. É à luz desse reconhecimento que toda uma nova área de ciéncia do sistema terrestre está em processo de ser desenvolvida. Por exemplo, o aumento de dióxido de carbono nos últimos anos tem sido pequeno, o que exige um longo período de cuidadosas medidas. Mas esse aumento está táo fortemente ligado aos oceanos, à biota e aos fenômenos de radiaçáo que, mesmo pequeno, pode ter sérias implicaçóes globais, de grande impacto sobre o clima, com todas as conseqüências. Portanto, devemos compreender o ciclo completo do dióxido de carbono, suas fontes e sumidouros, seus caminhos e a forma de circulação.

Temos de discriminar entre o que são flutuaçóes de ocorrência natural $e$ as antropogênicas antes de apresentarmos opçóes à sociedade (que podem ser caras, contra as aspiraçóes humanas comuns e retardantes do desenvolvimento) para redirecionar ou limitar certas atividades.

É nesse sentido que o ICSU tem seus principais projetos de natureza global, tais como o Programa Internacional de Geosfera e Biosfera (IGBP), o Programa Mundial de Pesquisa Climática (WCRP, junto a OMS e IOC), atividades do Comitê Científico sobre Problemas do Meio-Ambiente e de outros comitês científicos. Todos esses procedimentos estão ligados à compreensão dos vários aspectos que se relacionam com o sistema terrestre e suas interconexóes. O ICSU supervisiona essas atividades através do Comitê Consultivo sobre Meio-Ambiente. Existem agora novos planos para os Sistemas de Observação Global (GCOS), Oceanos (GOOS) e Sistemas Terrestres (CTOS). Há severa carência de cientistas em algumas disciplinas, importantes para a pesquisa sobre o sistema terrestre, e carência generalizada de cientistas nas 
partes em desenvolvimento do planeta. Criar capacitaçáo é, portanto, uma medida vital caso se pretenda que a ciência desempenhe um papel efetivo nessas áreas.

Dos vários capítulos da Agenda 21, pode-se destacar extensa lista de tópicos individuais nos quais a ciência tem um papel muito significativo a desempenhar se se pretende chegar a um desenvolvimento sustentável. Além das áreas de clima e de biodiversidade, que as pessoas normalmente associam à ECO-92, tem-se como outras áreas importantes a necessidade de satisfazer a demanda por água de uma já grande e crescente populaçáo; a proteçáo dos recursos do oceano, dos quais uma grande comunidade é dependente, não apenas em territórios insulares, mas ao longo de extensas costas; a satisfação das necessidades, em termos de agricultura, de uma população que certamente será de 8,5 bithóes em 2025 , dos quais mais de $\mathbf{8 0 \%}$ estarão vivendo em países subdesenvolvidos; a proteçáo de ecossistemas importantes e frágeis de montanha, nos quais vivem $10 \%$ da populaçáo mundial, muito vulneráveis a abalos sísmicos e erosão do solo; os cuidados com aspectos de segurança e gerenciamento de um crescente número de substâncias tóxicas e perigosas atualmente em uso, incluindo materiais radiativos; a tentativa de evitar maior degradação das terras e, em particular, o crescimento dos desertos. A lista pode ser maior.

É importante reconhecer que a população da Terra certamente excederá os 8,5 bilhóes num nível de saturação. E poderá chegar a um alarmante nível de 15 bilhóes se, exatamente a partir de agora, não cuidarmos do crescimento. O que a ciência pode fazer pela estabilização da população? O ICSU tem um Grupo de Estudos, sobre o tema, e as principais Academias de Ciências do mundo estão agora realizando uma reunião, em outubro de 1993. Globalmente, o que a ciência deveria fazer para satisfazer as necessidades humanas básicas, particularmente da grande população do mundo subdesenvolvido, de forma a que a dignidade humana seja preservada? As necessidades energéticas văo aumentar dos atuais 11 a 13 TW até $22-26 \mathrm{TW}$. Como fornecer tal quantidade de energia nos lugares onde é necessária e, ao mesmo tempo, fazer com que tal fornecimento não tenha implicaçóes adversas severas contra o meioambiente?

É evidente que, ao lado do crescimento da ciência pela ciência, a comunidade científica mundial deve dirigir seus esforços para permitir que a ciência seja aplicada de forma a garantir o desenvolvimento sustentável. Existem realidades acerca de população, energia, demandas básicas e outras, não facilmente alteráveis. O papel das ciências é conhecer os fatos bem como o seu grau de incerteza, avaliar as implicaçóes possíveis, 
encontrar formas de reduzir os mecanismos causadores adversos e propiciar, à sociedade, desenvolvimento dentro dessas limitaçóes.

Mas os cientistas também terão de reconhecer que, enquanto ciência e tecnologia são importantes, a transformação social o é ainda mais. Existem muitas formas através das quais, mesmo hoje, podemos mitigar aspectos das alteraçóes globais, e contribuir para uma diminuição significativa da pobreza. Mas isso náo está acontecendo. O problema está na esfera crucial das relaçóes humanas. Os cientistas devem se aperceber de que, além de desenvolver a ciência e suas aplicaçóes no sentido do desenvolvimento sustentável, a ciência deve forjar laços com outros setores da sociedade: com ciências sociais e engenharia, com negócios e indústria, com organizaçóes governamentais e intergovernamentais e, mais importante, com os setores náo-governamentais independentes que voluntariamente trabalham diretamente com a sociedade. A comunidade científica deve reconhecer que é parte da sociedade e deve contribuir para as transformações sociais, elas sim essenciais para o desenvolvimento sustentável.

A consciência científica internacional está alerta e trabalhando para unir recursos, tanto físicos como morais, necessários para que se tenha um desenvolvimento sustentável.

\title{
Ciência e Tecnologia: O Problema da Criação de Capacidade no Terceiro Mundo
}

\author{
ROBERTO LEAL LOBO E SIVVA FILHO \\ (Instituto de Física e Quimica da USP de São Carlos, Brasil)
}

hiato tecnológico entre os países desenvolvidos e os chamados em
desenvolvimento, longe de diminuir, como se esperava alguns anos
atrás, parece estar constantemente aumentando. A continuar essa ten-
dência, os países em desenvolvimento permaneceráo como uma promes- 